\title{
JOSÉ MUJICA: “O PRESIDENTE TUPAMARO" - DA LUTA ARMADA ÀS VIAS DEMOCRÁTICAS
}

\author{
Por Dércio Fernando Moraes Ferrari ${ }^{1}$
}

\begin{abstract}
Resumo
A escalada de José Mujica dentro da política uruguaia teve início ainda na década de 1970, durante sua luta junto ao Movimiento de Liberación Nacional-Tupamaros (MLNT), que surgiu no pré-golpe e foi suprimido durante a ditadura. Após militar junto ao grupo e ter ficado em cárcere durante 13 anos, Mujica teve sua liberdade na década de 1980, retomando assim suas atividades políticas e filiando-se a Frente Ampla (FA) via Movimiento de Participación Popular (MPP). Em liberdade, iniciou uma caminhada política dentro do país, onde foi deputado em 1994, Senador em 1999, Ministro da Agricultura, Pecuária e Pesca em 2005 e o ápice de sua escalada política seria a conquista da presidência uruguaia, a qual ocorreu nas eleições de 2009, onde venceu o candidato de um tradicional partido uruguaio, o Partido Nacional. A eleição de Mujica representa a continuidade de um governo de centro-esquerda no país, bem como o grande desenvolvimento das questões sociais, como a regulamentação da Cannabis psicoativo e a descriminalização do aborto. $\mathrm{O}$ objetivo deste trabalho é resenhar a trajetória política de Mujica desde o período de guerrilheiro tupamaro até a sua chegada ao posto político máximo uruguaio.
\end{abstract}

Palavras-chave: José Mujica; Frente Ampla (FA); Movimiento de Liberación NacionalTupamaros (MLN-T).

\begin{abstract}
José Mujica climbing inside the Uruguayan politics began in the 1970s, during your fight in the National Liberation Movement-Tupamaros (MLN-T), that has emerged in the precoup and was suppressed during the dictatorial period. After fight together the MLN-T and have been in jail during thirteen years, Mujica had you freedom in the 1980s, backing to yours political activities and joined to the Board Front (BF). Released, Mujica began his political walk inside the country, when be congressman in 1994, Senator in 1999 , Minister of Agriculture, Forestry \& Fishing in 2005 and the apex of your political walk was the chair presidential in 2009, when won the candidate of one Uruguayan traditional party, the National Party. The Mujica's arrival in the power, represent the permanence of the center-left in the charge, as well as the biggest development of the social questions, like the regulation of Cannabis psychoactive and the decriminalization of the abortion. The objective of this work is reviewing the political trajectory of Mujica since the time of tupamaro guerrilla until his arrival at the highest Uruguayan political post.
\end{abstract}

Keywords: José Mujica; Board Front (BA); National Liberation Movement-Tupamaros (MLN-T).

\footnotetext{
${ }^{1}$ Licenciado em História e Ciências Biológicas, Mestrando em Ciências Sociais, Unioeste, Toledo-PR.
} 


\section{INTRODUÇÃO}

José Alberto Mujica Cordano, conhecido como "Pepe", nasceu em 20 de maio de 1935 na cidade de Montevidéu sendo eleito Presidente da República Oriental do Uruguai em 2009, com um mandato de cinco anos. Mujica veio de uma família de pequenos agricultores nos arredores de Montevidéu, onde tem vivido desde seu nascimento. Ficando órfão de pai aos nove anos de idade, sua profissão desde muito cedo foi agricultor. Logo em sua juventude, Mujica se viu atraído para as lutas sociais dentro de seu país, sempre com as tendências socialistas e de esquerda.

Durante sua infância, pela ausência do pai Mujica revendia as flores produzidas na pequena propriedade da família na região de Montevidéu. Ainda na juventude, Mujica sente-se incomodado com as questões sociais e a concentração política presente em seu país e inicia sua luta contra o sistema bipartidário, juntamente com outros grupos de ideologia de esquerda.

O bipartidarismo sempre foi forte no Uruguai, dividindo o país entre os partidos Blanco e Colorado. Tal bipartidarismo só teve seu fim em 1971 com o surgimento da Frente Ampla (FA), partido de coalizão que havia surgido na década anterior. Os anos iniciais de Mujica na militância foram no Partido Nacional (Blanco), que futuramente seria seu partido de oposição, já que se aliaria a FA na luta contra a ditadura.

No contexto político que surge a FA, a esquerda no Uruguai tinha inexpressividade ${ }^{2}$, fato que pode ser comprovado pelo bipartidarismo em que ambos os partidos não tinham tendências esquerdistas e dominavam o cenário político do país desde sua independência em 1825. Desta forma objetiva-se com este trabalho analisar a escalada de José Mujica dentro da política uruguaia a partir de sua luta junto ao Movimento de Liberação Nacional - Tupamaros (MLN-T) na década de 1970, chegando as vias eleitorais ainda na década de 1990, sendo deputado em 1994, senador em 1999 e presidente em 2009.

Foi no cargo de deputado que Mujica ganhou notoriedade dentro do país. No início tal visibilidade veio por seus discursos humanitários e voltados para o campo e a integração entre o urbano e o rural. Logo também sua forma de vida austera chamou a

\footnotetext{
${ }^{2}$ A esquerda nesse momento destacavam-se principalmente nos movimentos sociais e armados, como foi o caso do Movimiento de Izquierda Revolucionário (MIR), do Movimiento Revolucionário Oriental (MRO), o Movimiento de Acción Popular Uruguay (MAPU), a Federación Anarquista Uruguaya (FAU) e o Movimiento de Apoyo Campesino (MAC). Ambos movimentos mesclavam em sua ideologia o marxismo, leninismo e em alguns casos o anarquismo.
} 
atenção da população, haja visto que o velho tupamaro manteve a mesma forma de vida desde os tempos da guerrilha no MLN-T.

\section{A MILITÂNCIA JUNTO AO MLN-T E O RETORNO À DEMOCRACIA}

A Ditadura Uruguaia (1973-1985) teve início durante o governo de Juan María Bordaberry por meio de um Golpe de Estado em 27 de junho de 1973, que viera por dissolver o Parlamento e acabar com as liberdades civis, tendo seu fim somente em 28 de fevereiro de 1985. Nesse período o Uruguai entrara em uma onda ditatorial que pairava sob a América do Sul, onde no país houve a censura política, colocando os partidos políticos na ilegalidade, perseguição, tortura e morte aos opositores do governo, onde consequentemente surgiram uma série de grupos contra o regime ditatorial. A contestação da ditatura no Uruguai foi ainda mais intensa desde seu início pela tradição democrática do país, haja visto seu surgimento como resultado de uma reforma agrária e o legado artiguista do século XIX.

O MLN-T eclodiu no Uruguai nos anos 1960, cerca de uma década antes do Golpe de Bordaberry, unindo as mais variadas camadas sociais com ideais de contestação ao sistema e autodefesa, numa tentativa de responder à crise estrutural vivenciada pelo pequeno país sul-americano naquele momento.

Segundo Porzecanski (1973, p. 15) o termo tupamaro "vem de Túpac Amaru II, o famoso imperador inca que entre 1780-1781 tentou libertar seu povo dos espanhóis". Os tupamaros - nome que os guerrilheiros adeptos ao MLN-T receberam - surgiram com uma tática de luta contra a conjuntura social da época e inspirada na Revolução Cubana ${ }^{3}$ : realizando sequestros, assaltos a bancos e de fato "a ideologia dos tupamaros nunca foi apresentada oficialmente em nenhum documento. De fato, os tupamaros nunca acreditaram na política e nos líderes de governo de sua época”.

A inspiração na Revolução Cubana ocorreu pois a mesma representou um exemplo prático de uma transformação social e radical por meio da revolução armada, assim como outros movimentos revolucionários que eclodiram no continente ${ }^{4}$, como

\footnotetext{
${ }^{3} \mathrm{Nem}$ todos autores concordam nesse ponto, visto que a ideologia tupamara nunca foi explicitada, uma vez que o movimento acabou por perder muito de sua origem inicial ao longo dos anos.

${ }^{4}$ No mesmo contexto que surge o MLN-T outros movimentos também destacaram-se na América do Sul, como é o caso do Sendero Luminoso no Peru, as Forças Armadas Revolucionárias da Colômbia (FARC), o Ejército Revolucionario del Pueblo na Argentina e a Guerrilha do Araguaia no Brasil, que embora em contextos e conjunturas diferentes buscaram em sua maioria a contestação.
} 
ressalta Hobsbawm (1995, p. 426-427), “os rebeldes latino-americanos na década de 1950 inevitavelmente se viram não só recorrendo à retórica de seus libertadores históricos, de Bolívar a José Martí da própria Cuba, mas à tradição anti-imperialista e socialrevolucionária da esquerda pós-1917’.

O MLN-T não se configurou como o único movimento de guerrilha uruguaio a agir durante o período (1969-1972), como destaca Lessa (2002, p. 21):

Durante a década de ações armadas dos Tupamaros (1963-1972) também surgiram outros grupos guerrilheiros de menor relevância, como a Organización Popular Revolucionaria 33 (POR 33) e as Fuerzas Armadas Revolucionarias Orientales (FARO). Em 16 de julho de 1969 a OPR 33 realizou uma de suas mais espetaculares e polêmicas operações: el robo a la bandera de los Treinta e Tres Orientales, que nunca foi devolvida. Em 3 de setembro do mesmo ano se teve conhecimento ao primeiro comunicado das FARO, mediante a qual se atribuíram algumas ações que as forças de segurança haviam atribuído responsabilidade ao MLN. Porém nenhuma dessas organizações aproximou-se do desenvolvimento dos Tupamaros.

Dentre tais grupos, o que teria maior repercussão e que já havia iniciado suas ações antes mesmo da ditadura, foi o Movimiento de Liberación Nacional-Tupamaros (MLN-T), fundado por Raul Séndic, ao qual Mujica juntou-se no Partido Socialista do Uruguai (PSU) formando assim a União Popular. O grande diferencial do MLN-T dos demais movimentos guerrilheiros foram suas ações predominantemente urbanas, o que também se apresentava como um desafio, pois Montevidéu caracterizava-se como uma das maiores aglomerações urbanas do continente e dava assim ao grupo problemas peculiares de grandes áreas urbanas, como grande visibilidade e vulnerabilidade, exigindo assim estratégias que contornassem tais agravantes. De tal forma a zona rural do país era utilizada na maioria das vezes apenas como esconderijo e depósito de armas.

A luta tupamara no Uruguai tem um significado de contestação políticoeconômica, sendo responsável - ainda que derrotada militarmente em 1972 - por expor deficiências sociais e econômicas presentes no país na década de 1970. No processo de retorno à democracia a participação do grupo foi focada em suas ações políticas juntamente a $F A$, uma coalizão de esquerda que já havia surgido em 1971 e acabou por quebrar o bipartidarismo uruguaio no início do século XXI.

Inicialmente visando uma revolução socialista baseada nos ideais do leninismo, marxismo, anarquismo, na efetividade da Revolução Cubana por meio da luta armada e frente aos eventos que em 1973 desencadeariam a ditadura civil-militar uruguaia os 
tupamaros caracterizaram-se como o principal movimento de guerrilha sul-americano até sua derrota militar em 1972 e como ressalta Maria Ribeiro do Valle (2005, p. 15) "o foco guerrilheiro - a luta armada -, diante da ascensão da ditadura, surge como alternativa à via pacífica e à ilegalidade constitucional propagada pelos partidos comunistas".

Segundo Clara Aldrighi (2001, p. 97) a sociedade que os tupamaros desejavam para o futuro era concebida como uma negação da existente, porém naquele momento estavam mais claros e estabelecidos os aspectos que não se queriam produzir do que as propostas concretamente. Testemunhos e documentos falavam da construção de um sistema socialista em termos gerais, porém excluíam claramente a possibilidade da implantação de um regime do tipo soviético.

A conjuntura político-econômica que fez desencadear o movimento e sua estratégia, como o próprio Documento $\mathrm{n}^{\circ} 1$ tupamaro confirma e também o ex-tupamaro Eleutério Huidobro em “História de los Tupamaros” (1986, p. 133-134), foram fatores econômicos como a dívida externa, a pressão do imperialismo econômico e sua dependência, crises financeiras e a inflação. Já no campo social foram fatores como o aumento do custo de vida, o descaso com o salário mínimo, a queda do poder aquisitivo e a crise da previdência social. Por fim, no campo político, segundo o autor, foram fatores como a incapacidade por parte das classes dominantes em dar uma solução a crise econômica e a dos partidos políticos e as oligarquias em solucionar os problemas do país, causando desta forma a deterioração das camadas políticas, econômicas e sociais, desencadeando assim nos primeiros tupamaros o sentimento nacional de defesa, sem entanto almejar a tomada do poder.

No que refere-se a origem do MLN-T vale ressaltar que os membros inicialmente integrantes da fase de formação do movimento, de acordo com Cabral (2007, p.157) eram de "distintos grupos e partidos de esquerda - não comunista - os integrantes da nascente organização conhecida com El Coordinador somaram a participação de socialistas, anarquistas," integrantes ainda de vários outros grupos, como destaca Alfonso Lessa (2002, p. 24) como é o caso do Movimiento de Izquierda Revolucionário - MIR, do Movimiento Revolucionário Oriental - MRO, o Movimiento de Acción Popular Uruguay (MAPU), a Federación Anarquista Uruguaya (FAU) e o Movimiento de Apoyo Campesino (MAC). Constata-se assim, na origem tupamara a entrada de tais grupos, de esquerda e anteriores ao MLN-T, a heterogeneidade do movimento. 
Mujica, juntamente com tupamaros, agiram extremamente contra o capitalismo e favoráveis às ideias de esquerda, como um caso em específico que Elio Gaspari (2003) descreve, onde:

(...) os tupamaros, com 3 mil militantes, fizeram coisas nunca vistas e até mesmo difíceis de imaginar. Suas ações, iniciadas em 1968, eram românticas, vingativas e pirotécnicas. Eles assaltaram um cassino e devolveram as gorjetas dos crupiês pelo correio. Depenaram a mansão de um plutocrata e divulgaram que nela havia 400 mil dólares em dinheiro e barras de ouro (GASPARI, 2003, p 324).

Ao longo das ações dos tupamaros Mujica participou de uma série delas, como ele descreve no livro "Mujica” de Miguel Ángel Campodónico (1999), a qual chama atenção à ação que ficou conhecida como a "Tomada de Pando", ocorrida em outubro de 1969, onde os tupamaros ocuparam vários prédios públicos na cidade, de Pando, que fica a 32 quilômetros de Montevidéu. (LESSA, 2005, p. 102).

Dando sequência à sua luta junto aos tupamaros, Mujica acabou sendo baleado e preso em 1972 como prisioneiro da ditadura militar, onde junto com alguns dos principais dirigentes tupamaros ficou treze anos preso em quartéis uruguaios. Mujica e o grupo que se encontrava em cárcere foram submetidos a um regime de destruição física, moral e mental, sendo colocados em uma espécie de poço como técnica de tortura, onde saíam apenas para as refeições.

Precisar a participação do presidente tupamaro no movimento é complexo, pois existe uma compartimentação dos arquivos policiais e militares da época, bem como uma confusa informação apresentada pela mídia da época. Os primeiros reatos de "Facundo" (nome que Mujica recebera internamente no movimento) começaram a aparecer apenas após sua participação na expropriação das armas de José Pedro Púrpura (ISRAEL, 2010, p. 65-66).

Em 1985, com o fim da ditadura, os presos políticos receberam anistia, como foi o caso de Mujica, que logo após ficar em liberdade juntou-se a outros membros anistiados do MLN-T no Movimento de Participação Popular (MPP), órgão dentro da FA que abrange principalmente os protagonistas na luta contra a ditadura ${ }^{5}$.

5 É importante ressaltar que a ideia da entrada do MLN-T na FA, incialmente não agradou os frenteamplistas nem os tupamaros, fazendo que em ambos os lados vários membros desvinculassem-se do movimento e do partido. 
Nesse momento tal grupo entra na luta contra o bipartidarismo, que foi uma presença marcante no Uruguai até o surgimento da FA, caracterizado como um partido de centro-esquerda que surgira com força tal qual nenhum outro partido teve no pósditadura.

As tentativas de partidos de coalizão que existiam antes da ditadura não sobreviveram a esse período, pois tiveram seus seguidores mortos, desaparecidos ou exilados, não retornando assim após 1985, diferentemente do que houve com a FA que se reestabeleceu após 1985, até com mais força política do que no período pré-ditadura.

Apesar de a FA ter se estabelecido como um partido político ainda no préditadura, só chegaria ao poder nacional em 2004, com a eleição do frenteamplista Tabaré Vázquez, onde nota-se uma mudança propriamente dita na conjuntura política uruguaia, uma vez Vázquez marca o primeiro governo de centro-esquerda no país desde sua independência.

No mesmo contexto, não somente o Uruguai presenciou a chegada de lideranças de esquerda ou centro-esquerda no poder, o mesmo ocorreu na Venezuela com Hugo Chávez (1999), no Brasil com Lula (2002), na Argentina com Néstor Kirchner (2003), na Bolívia com Evo Morales (2006) e no Chile com Michelle Bachelet (2006) (AYERBE, 2008, p. 265).

Ao analisar essa conjuntura mais profundamente - o que não caracteriza como objetivo deste trabalho - observa-se que tais mudanças não foram somente políticas, mas sim de profunda transformação social em alguns casos, onde ocorrera uma ruptura com os vestígios do neoliberalismo dos anos 1990.

Com o fim da ditadura, tem início o processo de redemocratização uruguaio com as eleições gerais, cujo fora a primeira vez em 13 anos que a população voltava às urnas e com a criação de uma lei de anistia (Lei da Caducidade) - algo similar ao que foi feito no Brasil e em alguns países latino-americanos no pós-ditadura entre as décadas de 1970 e 1980 - que deu anistia aos militares e civis envolvidos na ditadura.

A FA, que havia sobrevivido ao autoritarismo ditatorial, mas não teve força política suficiente para chegar à presidência no período de pós-redemocratização, "elege nas eleições de 1984 seis senadores e 21 deputados." De um modo geral, o período posterior a 1984 foi de crescimento para FA, pois logo em 1989 Tabaré Vásquez chega à prefeitura de Montevidéu, onde a FA já comandando a capital uruguaia há 25 anos. "A Frente Ampla ganha credibilidade ao governar Montevidéu” (PRESTES, 2011). 
Nos anos 1990 o Uruguai viu-se obrigado a realizar as reformas liberais, principalmente no setor previdenciário, visto que no período ditatorial o governo militar não realizou mudanças nesse setor, pois "o Uruguai tinha um sistema previdenciário de 'benefício definido' que pagava muito mais aos beneficiários do que recebia em contribuições" (COUTINHO; LIMA, 2007, p. 213).

Em 1994, quando Julio María Sanguinetti assume a presidência uruguaia, uma série de tentativas de reforma já haviam sido feitas, porém, todas sem sucesso. O grande legado de Sanguinetti em seu segundo mandato acabou por ser uma proposta de reforma mais profunda baseada em um diagnóstico mais completo dos problemas do sistema previdenciário e uma análise cuidadosa de cada um dos obstáculos às mudanças (COUTINHO; LIMA, 2007, p. 114).

As reformas propostas por Sanguinetti foram aprovadas pelo parlamento em 1996, criando um sistema previdenciário híbrido. O funcionamento dessas reformas ocorreu de forma que:

(...) os trabalhadores têm suas próprias contas e sabem o quanto depositaram nelas - com o princípio de solidariedade e benefícios públicos. O Banco da Previdência do Uruguai continua a administrar um pacote básico de benefícios que está disponível para todos os cidadãos, enquanto uma combinação de companhias públicas e privadas de administração de fundos de pensão administram contas individuais. Os contribuintes podem escolher qual dessas companhias, conhecidas como AFAPs pelas suas iniciais em espanhol, irá administrar suas contas (COUTINHO; LIMA, 2007, p. 112).

As reformas estabelecidas por Sanguinetti acabaram por colocar o país em um clima de crescimento econômico e que atraiu investimentos exteriores nos próximos anos.

Após tais reformas, a centro-esquerda, representada pela FA continuou em crescimento efetivo enquanto número de eleitos, tendo seu auge com a eleição de Tabaré Ramón Vázquez Rosas ${ }^{6}$ em 2004. Vázquez, que é formado em medicina, ex-líder da FA, ex-prefeito de Montevidéu pelo mesmo partido, marca em 2004 um fato histórico para o Uruguai ao ser o primeiro presidente de centro-esquerda do país.

A eleição de Vázquez, além de outros fatores significou a ruptura efetiva entre o bipartidarismo, pois por mais que a FA já havia feito isso em outros órgãos

\footnotetext{
${ }^{6}$ Nas eleições de outubro de 2014 Vázquez tenta seu segundo mandato presidencial pela FA, tendo vencido Constanza Moreira na votação interna do partido e obtendo cerca de $43 \%$ nas eleições de primeiro turno em outubro de 2014.
} 
administrativos - como na prefeitura de Montevidéu - era a primeira vez que a esquerda ou centro-esquerda chegava à presidência da república, onde na ocasião Vázquez recebera $50,7 \%$ dos votos contra o segundo colocado, do Partido Colorado.

A eleição de Vázquez marca ainda a adesão do interior do país a um partido de esquerda, visto que a capital já estava sob o governo da FA desde 1989, o que foi ponto positivo para o governo, pois Vázquez contou com “[...] maiorias parlamentares, experiência acumulada em três períodos consecutivos de governo municipal em Montevidéu e a recuperação do jogo democrático, que permitiu a ascensão sem sobressaltos da esquerda ao governo" (CHIRICO, 2006, p. 58).

O governo de Vázquez cumpriu em suma sua agenda de campanha eleitoral, como pode ser notado em algumas medidas adotadas de imediato por Vázquez durante seu governo, como "o restabelecimento da negociação salarial nos Conselhos de Salários; a implementação do Plano de Emergência Social (PANES) e a reforma tributária e aplicação do imposto de renda sobre pessoas físicas (IRPF)" (RODRÍGUEZ e VAIRO, 2010, p. 29).

Ao fim de seu governo, em março de 2010, Vázquez deixa o país com um PIB (Produto Interno Bruto) 30\% maior em relação a 2005 e possuindo $60 \%$ de aprovação da população uruguaia, deixando assim as portas abertas para um sucessor frenteamplista.

\section{A ASCENSÃO POLÍTICA DE JOSÉ MUJICA}

Com o retorno à democracia, Mujica, juntamente com o MNL-T e a FA retomam suas atividades que estiveram estagnadas durante todo período ditatorial. A metodologia utilizada pelos frenteamplistas nesse momento foi a de aproximação dos setores públicos e sociais, inclusive da elite, que até então apresentara resistência contra a ideologia de esquerda. A liberdade de Mujica deu ainda mais força a seus ideais e sua luta contra o sistema, luta essa que já havia iniciado ainda antes da ditadura. A aliança oficial de Mujica com a FA, por meio do Movimento de Participação Popular só se deu em 1989 quando o próprio MLN-T se uniu a FA.

A entrada de Mujica na FA marcaria a sua filiação novamente a um partido político e de acordo com Sergio Israel (2010, p. 14) Mujica teria iniciado sua trajetória política ainda na década de 1990, onde teria ganho visibilidade no país em um evento em que subira em um ônibus com uma placa contra a lei que previa regulamentar o setor de UTE (Usinas e Transmissões Elétricas) e colocar sua administração sob controle privado. 
Em 1995, influenciado por Uberfil Hernández, Mujica candidata-se e é eleito então deputado. Já em 1999 foi eleito Senador e logo ganhou "uma considerável visibilidade pública com seu estilo nada formal: deslocava-se ao trabalho em uma simples motocicleta, vestia sempre a mesma jaqueta de lã e raras vezes penteava o cabelo ou aparava a barba" (DUARTE, 2011, p. 83).

No Parlamento Mujica adotou uma postura indolente porém construtiva. No primeiro mês após eleito, depois de várias sessões sem se pronunciar Mujica enviou uma carta ao Presidente da Câmara, Guillermo Stirling solicitando meia hora para realizar seu primeiro discurso. No referido discurso Mujica optou por falar sobre a questão do campo e uma política nacional, onde na época foi motivo de crítica por muitos, principalmente pela temática abordada e seu modo de vestir-se. Porém tais discursos a longo prazo agradaram os eleitores, que em 2009 fizeram com que a FA tivesse o primeiro presidente da esquerda eleito na capital e o mais votado naquela região (ISRAEL, 2010, p.99-101).

A declaração abaixo foi dada por Mujica à revista "Brecha" em 1999 sobre como ele descreveria o político "Pepe" Mujica:

Pepe Mujica é um veterano, um velho que tem uns quantos anos de cárcere, de tiros no lombo, um tipo que se equivocou muito, como toda sua geração e que trata de, até onde é possível, ser coerente com o que pensa, todos os dias do ano e todos os anos da vida. E que se sente muito feliz, entre outras razões, por poder contribuir para representar aqueles que não estão e que deveriam estar (ZÁRATE, 2011).

Após 2002 Mujica passou a ser visto constantemente na mídia, onde a imagem do "Pepe" político começou a ser conhecida, pois até então o que ele representava era a imagem de um velho guerrilheiro que esteve preso pelo governo.

Em 2005 Mujica foi nomeado por Vázquez ministro da Agricultura, Pecuária e da Pesca e "estimulou o aumento da produção e a elevação da renda dos pequenos e médios produtores”. As ações de Mujica enquanto ministro da Agricultura foram positivas para a economia uruguaia, uma vez que o mercado consumidor externo foi ampliado, graças às ações de Mujica na relação com os países asiáticos, que ao aumentar os padrões de controle de qualidade dentro do país, o mercado internacional aumentou as importações de produtos de origem animal e vegetal e por último, mas não menos importante, "uma medida muito popular neste período foi convencer os produtores de carne para consumo doméstico a baixar os preços dos cortes bovinos mais consumidos pelos uruguaios" (DUARTE, 2011, p. 84). 
Foi nesse cargo que Mujica destacou sua capacidade política e administrativa, devido ao fato de que:

Teve a oportunidade de aplicar suas ideias para revitalizar a produção e, não menos importante, aumentar os níveis de renda dos pequenos e médios agricultores e fazendeiros coletivos do qual ele tinha sido um membro, em comparação com os grandes produtores. Desde o primeiro momento ele duvidou de sua formação técnica, pois era um homem sem faculdade e sem experiência na administração pública. A verdade é que o ministro, que trouxe a visão política, tomada com a de um agrônomo do Movimento de Participação Popular e ex-guerrilheiro Ernesto Agazzi Sarasola, nomeando-o vice-ministro (ZÁRATE, 2011).

A reputação adquirida por Mujica durante seu mandato como ministro se deu principalmente por suas realizações, mas também pela sua linguagem coloquial e o fato de não possuir "papas na língua". Em 2008, quando sua popularidade já havia sido edificada, Mujica renuncia ao cargo de ministro da Agricultura, Pecuária e da Pesca, passa o cargo para Ernesto Agazzi para poder iniciar sua caminhada para a presidência no ano seguinte pela FA.

Em 2008 muito se falou sobre a eleição de Mujica, onde alguns (inclusive companheiros de Mujica) começaram a difundir a ideia de que ele não seria um bom presidente pois era um dirigente de massas, não um dirigente político, como afirmava o também ex-tupamaro Ernesto Agazzi. Já Julio Merenales, fundador e representante da ala mais ortodoxa do MLN-T acreditava que Mujica não poderia ser presidente, pois o cargo exigia coisas que um verdadeiro tupamaro não poderia fazer. $\mathrm{O}$ temor de muitos naquele momento era ainda de que Mujica enquanto ex-guerrilheiro pudesse interferir negativamente na angariação de votos para a FA (ISRAEL, 2010, p. 130-131). Tal medo era consequência direta do resultado nas eleições anteriores, onde o passado tupamaro dos candidatos era levantado e posto de forma negativa perante o público.

Ainda em 2008, outro conflito envolvendo a possibilidade da candidatura de Mujica ocorreu, visto que falava-se naquele momento em um movimento reeleicionista por parte dos aliados de Vázquez, ainda que o mesmo tenha negado inúmera vezes estar compactuando com tal movimento. A candidatura oficial de Mujica só foi declarada no fim de 2008, resultado de um acordo histórico entre o MPP e o PCU (Partido Comunista Uruguaio), que pretendia apresentar Constanza Moreira como candidata interna do partido.

Porém em 2009, após muitas reuniões e conversas informais, mesmo que com anseios presidenciais Mujica teve que enfrentar a votação interna da FA, onde seu maior 
oponente foi Danilo Astori (que posteriormente seria seu vice presidente), ex-ministro da Economia de Vázquez, que possuía os mesmos anseios que Mujica. Mas “ainda estiveram na disputa o ministro da Indústria, Energia e Mineração, Daniel Martinez, o diretor do Escritório de Planejamento e Orçamento da Presidência, Enrique Rubio e o prefeito de Canelones, Marcos Carámbula" (WEISSHEIMER, 2008). Nesse momento Mujica buscava então consolidar sua figura política, partindo para uma aproximação da população.

A figura de Eleutério Fernández Huidobro também foi de grande influência para a escolha da fórmula Mujica-Astori, visto que dentre os ex-tupamaros foi o primeiro a cogitar a hipótese de uma união entre Mujica e Astori, que oficialmente só iria ocorrer após a votação interna.

$\mathrm{Na}$ votação interna, composta por 2.381 delegados da FA, "venceu Mujica (52,1\%), convidando Astori (39,6\%) para ser seu vice" (DUARTE, 2011, p. 84). Nas eleições de 2009 o Partido Colorado indicou Pedro Bordaberry para a presidência, o Partido Blanco indicou Luis Lacalle, o Partido Independente indicou Pablo Mieres e a FA após a votação interna indicou José Mujica.

Nesse contexto, o único que era de um partido de centro-esquerda era Mujica, porém, vale lembrar que os partidos tradicionais - Blanco e Colorado - dominaram a cadeira presidencial desde a independência do país. Os demais presidenciáveis também possuíam uma experiência política prévia, onde Pedro Bordaberry era o presidente do Partido Colorado e filho do ex-presidente Juan María Bordaberry, já Lacalle havia sido presidente da república entre 1990 e 1995. A vantagem que Mujica possuía sobre os demais era de seu antecessor, Tabaré Vázquez ter um alto índice de popularidade e também ser frenteamplista.

No primeiro turno Mujica obteve $48 \%$ dos votos contra $28 \%$ de Lacalle, o segundo colocado nos resultados eleitorais - o que não foi suficiente para a vitória no primeiro turno - levando assim a eleição presidencial para o segundo turno. No segundo turno, o Partido Blanco e o Partido Colorado, aliaram-se e:

Tentaram por todos os meios, durante a campanha eleitoral, desencorajar o voto na FA, tirando do armário velhos discursos eficazes nos anos 70 - a respeito do perigo representado pelos "Tupamaros" para a democracia. Insistiram até o cansaço na tese de que "uma vez guerrilheiro, sempre guerrilheiro", procurando semear desconfianças no compromisso com as instituições republicanas e com o respeito à Constituição de parte de José Mujica, hoje presidente eleito, 
que nos anos sessenta e setenta do século passado foi um dos líderes do movimento armado que dominou a cena política uruguaia (BISSIO, 2009).

Já a campanha eleitoral da FA não foi tão profunda no segundo turno, pois focou primordialmente nos sucessos de Vázquez e "a aparição de Mujica e Astori nos meios de comunicação, o que pretendia gerar uma noção da equipe e despersonalizar a eleição, minimizando, assim, as debilidades de Mujica...” (RODRÍGUEZ e VAIRO, 2010, p. 29). Nesse momento de campanha, Vázquez ainda apareceu algumas vezes junto à Mujica e Astori numa tentativa de consolidar o eleitorado frenteamplista ainda receoso com a nova chapa do partido.

Porém, mesmo com a campanha anti-Mujica dos partidos tradicionais, os resultados para o segundo turno foram positivos e "Pepe" obteve $52 \%$ dos votos, contra 43\% de Lacalle, dados esses que deram a Mujica a presidência e garantiram mais cinco anos de governo da FA na presidência uruguaia.

Logo após a vitória Mujica deu declarações à imprensa como forma de agradecimento e de que gostaria de um governo com a participação de todos, iniciando assim sua consolidação no poder. Logo de início se esperava que Mujica trilhasse uma linha semelhante à de Vázquez com "ênfase no combate à pobreza e exclusão social que caracterizou a primeira administração frenteamplista" (GARCE, 2010, p.14).

Durante a campanha presidencial, de fato Mujica prometeu em seu plano de governo manter a linha frenteamplista seguida por Vázquez, já que no Uruguai, naquele momento:

\footnotetext{
O tom socialdemocrata exaltava as altas taxas de crescimento do PIB e das exportações do período anterior, a drástica redução das paralisações salariais, os grandes investimentos públicos em educação, infraestrutura e tecnologia, a reforma tributária progressiva e a correção dos déficits sociais, com grande mérito para o PANES e o Plano de Igualdade Social (DUARTE, 2011, p. 87).
}

Mujica prometia aprofundar tais programas dentro de uma estratégia ampla de desenvolvimento nacional com prioridade para a educação. E assim o têm feito. As primeiras realizações no governo de Mujica começaram com projetos sociais, combatendo a pobreza e investindo em educação. Logo em suas primeiras declarações Mujica ganhou destaque internacional com sua proposta de que doaria $90 \%$ de seu salário - de um total equivalente R $\$ 25$ mil - à ONG's e entidades necessitadas e declarou que 
os $10 \%$ que lhe sobram são suficientes, uma vez que muitos uruguaios vivem com muito menos que isso.

Outras declarações, como foi o caso da Rio+20, onde deixou todos emocionados com seu discurso, onde o ponto alto foi seu questionamento, onde refletiu: "estamos governando a globalização, ou é a globalização que nos governa? É possível falar de solidariedade e que "estamos todos juntos", em uma economia baseada na concorrência impiedosa? Até onde chega nossa fraternidade?" O homem não governa hoje" (NASSIF, 2012). O modo de vida de Mujica é bem peculiar, se comparado aos demais líderes mundiais, pois cultiva hábitos simples, dirige seu Fusca 1987 e vive sem os regalos que o cargo pode oferecer.

A mídia internacional atribuiu a Mujica o título de "presidente mais pobre do mundo", o que ele logo rebate com seus argumentos socialistas, como o declarado durante sua campanha presidencial em 2009, onde segundo Mujica "temos de escapar da escravidão que impõe a dependência material, que é uma das coisas que mais roubam tempo na sociedade contemporânea. Se você se deixa arrastar pelas pressões da sociedade de consumo, não existe dinheiro que alcance, não tem fim, é infinito".

Mujica vive na mesma fazenda que vivera antes de ser eleito presidente e nas horas vagas continua agricultor e florista. Estas e outras atitudes fazem com que Mujica tenha um método de governo híbrido, não só na América Latina, mas a nível mundial.

Logo no início de seu mandato, "Mujica ressaltou a importância de priorizar a engenharia genética e a informática como ferramentas essenciais de inserção do Uruguai na sociedade do conhecimento, de forma a torná-lo uma região polo regional de alta tecnologia" (DUARTE, 2011, p. 84).

Um programa que merece destaque no governo de Mujica é a ampliação do Plano Ceibal, já em vigor no governo de Vázquez, que visa a distribuição de um computador portátil para cada estudante da rede pública de ensino, que tem como objetivo "promover a inclusão digital, a fim de reduzir o fosso digital em comparação com outros países, e entre os cidadãos do Uruguai, a fim de permitir mais e melhor acesso à educação e à cultura" (CEIBAL, 2013, nossa tradução).

Outra grande ação iniciada por Mujica e que merece atenção "é a isenção do imposto de renda para as camadas mais pobres, disputa na qual o empresariado uruguaio é o grande inimigo" (DUARTE, 2011, p.88). Ainda dentre os projetos tecidos ou apoiados por Mujica na presidência e de grande repercussão mundial temos a regulamentação da maconha, onde de acordo com o presidente é uma estratégia de política pública para o 
combate ao tráfico de drogas dentro do país, visto que todas as medidas tomadas anteriormente não obtiveram sucesso e a criminalidade cresce dentro do país que por muitos anos foi considerado um dos mais seguros de se viver no continente. Já a descriminalização do aborto também se estabelece como um projeto de destaque, que de forma híbrida no continente surge de modo a evitar a mote de mulheres pela prática clandestina de aborto no país.

As diferenças mais marcantes entre o governo de Mujica e seus antecessores seriam as relações regionais e o desenvolvimento social, uma vez que Mujica privilegiou a integração regional na América do Sul, onde Segundo Silva (2012);

Buscando superar as diferenças com os sócios do Mercosul, aproximouse dos governos de Argentina e Brasil. Com o Brasil, foram assinados diversos acordos, que tratavam das múltiplas esferas da integração infraestrutura, energia, produção -, além de promoverem a cooperação em ciência e tecnologia. O Uruguai apoiou ainda as aspirações brasileiras a um assento permanente no Conselho de Segurança da ONU (SILVA 2012, p. 314).

Em linhas gerais, as medidas tomadas por Mujica logo em 2010 acabaram por dar "resultados positivos em todos os ramos de atividade, destacando-se o comércio, transportes, comunicações e serviço, embora a evolução tenha sido lenta na indústria manufatureira e no setor primário" (DUARTE, 2011, p. 84).

As relações latino-americanas também foram estreitadas com o governo de Mujica, onde houve uma aproximação de tais países por parte do presidente uruguaio que acabou logo no primeiro ano de governo visitando vários destes países em momentos solenes.

\section{CONSIDERAÇÕES FINAIS}

A título de conclusão é nota-se que o Uruguai após passar por um período de ditadura nas décadas de 1970 e 1980 tem caminhado para uma nova conjuntura política, onde com a chegada da esquerda no poder novos atores políticos puderam ter ascensão dentro do país, como foi o caso de Vázquez e Mujica, uma vez que os mesmos marcam o fim do bipartidarismo. Dentre as organizações que contribuíram para essa mudança destaca-se o Movimento de Liberação Nacional-Tumparos (MLN-T) e a FA, onde cada qual teve seu importante papel nessa transformação pela qual passou e passa o Uruguai. 
O caso de Mujica em específico demonstra que o ex-guerrilheiro tupamaro, mesmo após ser preso e ter vivido nas piores condições possíveis durante a ditadura não perdeu seus ideais socialistas como pode ser comprovado com seu atual estilo de vida, fugindo à regra de um presidente da república, estilo esse que tem feito Mujica ganhar cada vez mais admiradores dentro e fora do Uruguai.

A escalada política de Mujica, que teve início pelas vias democráticas em 1994 manteve um perfil ideológico que o velho tupamaro mantinha ainda quando fazia parte do MLN-T. Ainda que a luta armada tenha ficado do passado, a entrada de Mujica na política busca

No ritmo de governo tecido até aqui por Mujica, prestes a completar seus últimos meses como mandatário, observa-se o cumprimento de várias de suas promessas de campanha e uma série de reformas sociais, como a descriminalização do aborto e a regulamentação da maconha. Na questão do aborto o objetivo do governo é reduzir o número de mortes de mulheres pela prática clandestina. Já na questão da maconha, Mujica estabelece que é uma tentativa de combate direto ao tráfico de drogas, visto que todas as medidas tomadas anteriormente não apresentaram resultados efetivos e os índices de criminalidade no país têm aumentado.

Tais temas tornam o Uruguai como referência social, principalmente no que se refere ao continente latino-americano, onde a maior parte desses países possui dificuldade em abordar tais problemáticas em suas agendas políticas. Por fim, observa-se que a forma de governo traçada por Mujica acabou por dar visibilidade ao Uruguai, proporcionando assim ainda um crescimento no turismo e a possibilidade para um sucessor frenteamplista.

\section{REFERÊNCIAS BIBLIOGRÁFICAS}

ALDRIGHI, Clara. La izquierda armada: Ideología, ética e identidad en el MLNTupamaros. Montevideo: Ediciones Trilce, 2001.

AYERBE, Luis Fernando. Novos atores políticos e alternativas de governo na América do Sul: os casos de Argentina, Bolívia, Brasil e Venezuela (p. 265-301). In: AYERBE, L. F. (Org.). Novas lideranças políticas e alternativas de governo na América do Sul. São Paulo: UNESP, 2008. 
BISSIO, Beatriz. A vitória de José Mujica. [Brasil], 2010. Disponível em: http://www.dialogosdosul.org.br/a-vitoria-de-jose-mujica/ Acesso em: 10 jul. 2014.

CAMPODÓNICO, Miguel Ángel. Mujica. 1. ed. Montevideo: Fin de Siglo, 1999.

CEIBAL. Plan Ceibal. Montevideo, 2013. Disponível em: http://www.ceibal.org.uy/index.php?option=com_content $\& v i e w=$ category \&layout=blog \&id=35\&Itemid=54. Acesso em: 16 jun. 2014.

CHIRICO, Selva López. Uruguai - Balanço de um ano de governo. Nossa América Revista do Memorial da América Latina, São Paulo, v. 23. 2006.

COUTINHO, Marcelo V. LIMA, Maria R (Orgs). A agenda sul-americana: mudanças e desafios do início do século XXI. Brasília: Fundação Antônio Gusmão, 2007.

DUARTE, Rafael Macedo. Ascensão e consolidação da Frente Ampla Uruguaia: da clandestinidade às vias democráticas, da esquerda tradicional ao progressismo. 2010. 104 f. Trabalho de Conclusão de Curso (Graduação em Ciências Econômicas) - Universidade Federal de Santa Catarina, Florianópolis, 2011.

GARCE, Adolfo. Uruguay 2009: de Tabaré Vàzquez a José Mujica. Rev. ciênc. polít. (Santiago), [online]. 2010, vol. 30, n. 2. p. 499-535. ISSN 0718-090X.

GASPARI, Elio. A ditadura derrotada. São Paulo: Companhia das Letras. 2003.

HOBSBAWM, Eric. Era dos Extremos: o breve século XX: 1914-1991. São Paulo: Companhia das Letras, 1995.

HUIDOBRO, Eleutério F. Historia de los Tupamaros: las origenes. Montevideo: TAE, Tomo I, 1986.

ISRAEL, Sergio. Mujica: El florista presidente. Montevideo: BUSQUEDA-Editorial Fin de Siglo, 2010 
LESSA, Alfonso. La revolución imposible: los tupamaros y el fracasso de la vía armada en el Uruguay del siglo XX. Montevidéu: Fin de Siglo, 2002

NASSIF, Luis. Luis Nassif Online. O discurso do presidente do Uruguai na Rio +20 . [Brasil], 2012. Disponível em: http://www.advivo.com.br/blog/luisnassif/o-discurso-dopresidente-do-uruguai-na-rio-20 Acesso em: 14 jan. 2014.

PORZECANSKI, Arturo C. Uruguay's Tupamaros: The Urban Guerrilla. New York: Praeger Publishers, 1973.

PRESTES, Felipe. Sul 21: Há quarenta anos nascia a esquerda tolerante no Uruguai. Porto Alegre, 2011. Disponível em: http://www.sul21.com.br/jornal/ha-quarenta-anosnascia-a-esquerda-tolerante-no-uruguai/ Acesso em: 30 jun. 2014.

RODRÍGUEZ, José Raúl e VAIRO, Daniela. Comportamiento electoral em Uruguay: dilucidando las claves del triunfo de José Mujica en las presidenciales de 2009. Em Debate, Belo Horizonte, vol. 2, n 4, p.27-35, abr. 2010.

SASSO, Rolando W. 8 de octubre de 1969 - La toma de Pando: La Revolución Joven. Montevideo: Fin de Siglo, 2005; p. 142.

SILVA, Roberta R. M. A política externa do Uruguai no período recente: as teorias das relações internacionais e os dilemas de um estado pequeno. In: Congresso de Relaciones Internacionales, 6., 2012, La Plata. Anais. La Plata: 2012. 16 p.

VALLE, Maria R. A violência revolucionária em Hannah Arendt e Herbert Marcuse: raízes e polarizações. São Paulo: Editora UNESP, 2005.

WEISSHEIMER, Marco Aurélio. Carta Maior: José "Pepe" Mujica é escolhido candidato da Frente Ampla à presidência do Uruguai. Porto Alegre, 2008. Disponível em: http://www.cartamaior.com.br/templates/materiaMostrar.cfm?materia_id=15434 Acesso em: 03 jan. 2014.

ZÁRATE, Roberto Ortiz (ed.). Centro de Estudios y Documentación Internacionales de Barcelona: Biografía de José Mujica Cordano. Barcelona, 2011. Disponível em: http://www.cidob.org/es/documentacion/biografias_lideres_politicos/america_del_sur/u ruguay/jose_mujica_cordano Acesso em: 25 jul. 2014. 